\title{
Universiteit
}

Leiden

The Netherlands

\section{Prognostic Influence of Feature Tracking Multidetector Row Computed Tomography-Derived Left Ventricular Global Longitudinal Strain in Patients with Aortic Stenosis Treated With Transcatheter Aortic Valve Implantation}

Gegenava, T.

\section{Citation}

Gegenava, T. (2020). Prognostic Influence of Feature Tracking Multidetector Row Computed Tomography-Derived Left Ventricular Global Longitudinal Strain in Patients with Aortic Stenosis Treated With Transcatheter Aortic Valve Implantation, 125(6), 948-955. doi:10.1016/j.amjcard.2019.12.024

Version: $\quad$ Not Applicable (or Unknown)

License: $\quad$ Leiden University Non-exclusive license

Downloaded from: $\quad$ https://hdl.handle.net/1887/3232582

Note: To cite this publication please use the final published version (if applicable). 


\title{
Prognostic Influence of Feature Tracking Multidetector Row Computed Tomography-Derived Left Ventricular Global Longitudinal Strain in Patients with Aortic Stenosis Treated With Transcatheter Aortic Valve Implantation
}

\author{
Tea Gegenava, MD, PhD ${ }^{\mathrm{a}}$, Pieter van der Bijl, MBChB, MMed ${ }^{\mathrm{a}}$, E. Mara Vollema, MD ${ }^{\mathrm{a}}$, \\ Frank van der Kley, MD ${ }^{\mathrm{a}}$, Arend de Weger, MD ${ }^{\mathrm{b}}$, David Hautemann, MSc ${ }^{\mathrm{c}}$, Johan H.C. Reiber, $\mathrm{PhD}^{\mathrm{c}}$, \\ Nina Ajmone Marsan, MD, $\mathrm{PhD}^{\mathrm{a}}$, Jeroen J. Bax, $\mathrm{MD}, \mathrm{PhD}^{\mathrm{a}}$, and Victoria Delgado, $\mathrm{MD}, \mathrm{PhD}^{\mathrm{a}}$ *
}

Computed tomography plays a central role in the evaluation of patients with severe aortic stenosis who underwent transcatheter aortic valve implantation (TAVI). Advances in left ventricular (LV) analysis with multidetector row computed tomography (MDCT) permit measurement of LV global longitudinal strain (GLS). The present study aimed at evaluating the association between feature tracking (FT) MDCT derived LV GLS and all-cause mortality in patients treated with TAVI. A total of 214 patients with severe aortic stenosis $(51 \%$ male, $80 \pm 7$ years) who underwent TAVI and with dynamic MDCT data allowing LV GLS measurement with novel FT algorithm were included. LV GLS was measured at baseline and were divided according to a previously published cut-off value of LV GLS associated with all-cause mortality ( $\leq-14 \%$ [more preserved LV systolic function] vs $>-14 \%$ [more impaired $\mathrm{LV}$ systolic function]). Patients were followed for the occurrence of all-cause mortality. Mean FT MDCT-derived LV GLS was $-12.5 \pm 4 \%$. During a median follow-up of 45 months (interquartile range: 29 to 62 months), $67(31 \%)$ patients died. The cumulative rate of all-cause mortality for the patients with FT MDCT-derived LV GLS $\leq-14 \%$ was $15 \%$ versus $28 \%$ for the patients with FT MDCT-derived LV GLS $>-14 \%$, Log rank $p=0.001$ ). FT MDCT-derived LV GLS was independently associated with all-cause mortality (hazard ratio: $0.851 ; 95 \%$ confidence interval: 0.772 to $0.937 ; p=0.001$ ). In conclusion, impaired FT MDCTderived LV GLS is independently associated with all-cause mortality in patients treated with TAVI. Besides aortic valve area and calcification, FT MDCT-derived LV GLS is an important prognostic marker. ๑ 2019 Elsevier Inc. All rights reserved. (Am J Cardiol 2019;00:1-8)

Transcatheter aortic valve implantation (TAVI) is a minimally invasive treatment option for patients with severe aortic stenosis (AS) regardless of the operative risk. ${ }^{1-4}$ Currently, this treatment is recommended in symptomatic severe AS and

\footnotetext{
${ }^{a}$ Department of Cardiology, Leiden University Medical Center, Leiden, The Netherlands; ${ }^{b}$ Department of Cardio-Thoracic surgery, Leiden University Medical Center, Leiden, The Netherlands; and 'LKEB, Leiden University Medical Center, Leiden, The Netherlands. Manuscript received September 15, 2019; revised manuscript received and accepted December 17, 2019.

Author agreement:

1. All authors have participated in the work and have reviewed and agree with the content of the article.

2. None of the article contents are under consideration for publication in any other journal or have been published in any journal.

3 . No portion of the text has been copied from other material in the literature (unless in quotation marks, with citation).

4. I am aware that it is the author's responsibility to obtain permission for any figures or tables reproduced from any previous publications, and to cover fully any costs involved. Such permission must be obtained before final acceptance.

See page 6 for disclosure information

*Corresponding author: Tel: +31715262020; fax: +31715266809.

E-mail address: v.delgado@lumc.nl (V. Delgado).
}

are at least at intermediate operative risk. ${ }^{5}$ Left ventricular ejection fraction (LVEF) is one of the prognostic markers in patients with severe AS. However, LVEF may not be the ideal parameter for risk stratification of patients with severe AS since it may remain within the normal range for a long time despite changes in the myocardial structure such as hypertrophy and replacement fibrosis. ${ }^{6}$ In contrast, left ventricular (LV) global longitudinal strain (GLS) has been shown to correlate better with LV remodeling induced by pressure overload and has incremental prognostic value over LVEF. ${ }^{7-9}$ Feature tracking (FT) multidetector row computed tomography (MDCT) data analysis permits assessment of LV GLS and may become an important adjuvant tool for risk stratification of patients with severe AS by adding functional data to well-known anatomical prognostic parameters such as aortic valve calcification burden. ${ }^{18}$ The present study evaluated the association between FT MDCT-derived LV GLS and allcause mortality in patients with severe AS who underwent TAVI. In addition, the incremental prognostic value of FT MDCT-derived LV GLS over anatomical prognostic markers such as aortic valve area and aortic valve calcification was investigated. 


\section{Methods}

This retrospective analysis included a total of 214 patients with severe AS, treated with TAVI who underwent MDCT and had complete echocardiographic evaluation within 3 months of the MDCT data acquisition. Of 230 randomly selected patients of the overall population treated with TAVI between December 2007 and July 2017, 16 patients were excluded because of lack of appropriate computed tomography data for analysis. Severe AS was defined according to current recommendations: an aortic valve area
$<1.0 \mathrm{~cm}^{2}$ or indexed aortic valve area $<0.6 \mathrm{~cm}^{2} / \mathrm{m}^{2}$, peak aortic jet velocity $\geq 4 \mathrm{~m} / \mathrm{s}$ and a mean transvalvular pressure gradient $\geq 40 \mathrm{~mm} \mathrm{Hg} .{ }^{11}$ For retrospective analysis of clinically acquired data the institutional review board waived the need for written patient informed consent.

Clinical data included demographics, cardiovascular risk factors, symptoms, medications, and operative mortality risk calculated according to the logistic European System for Cardiac Operative Risk Evaluation (euroSCORE). All clinical data were collected from the Cardiology Department Information System (EPD-Vision; Leiden University
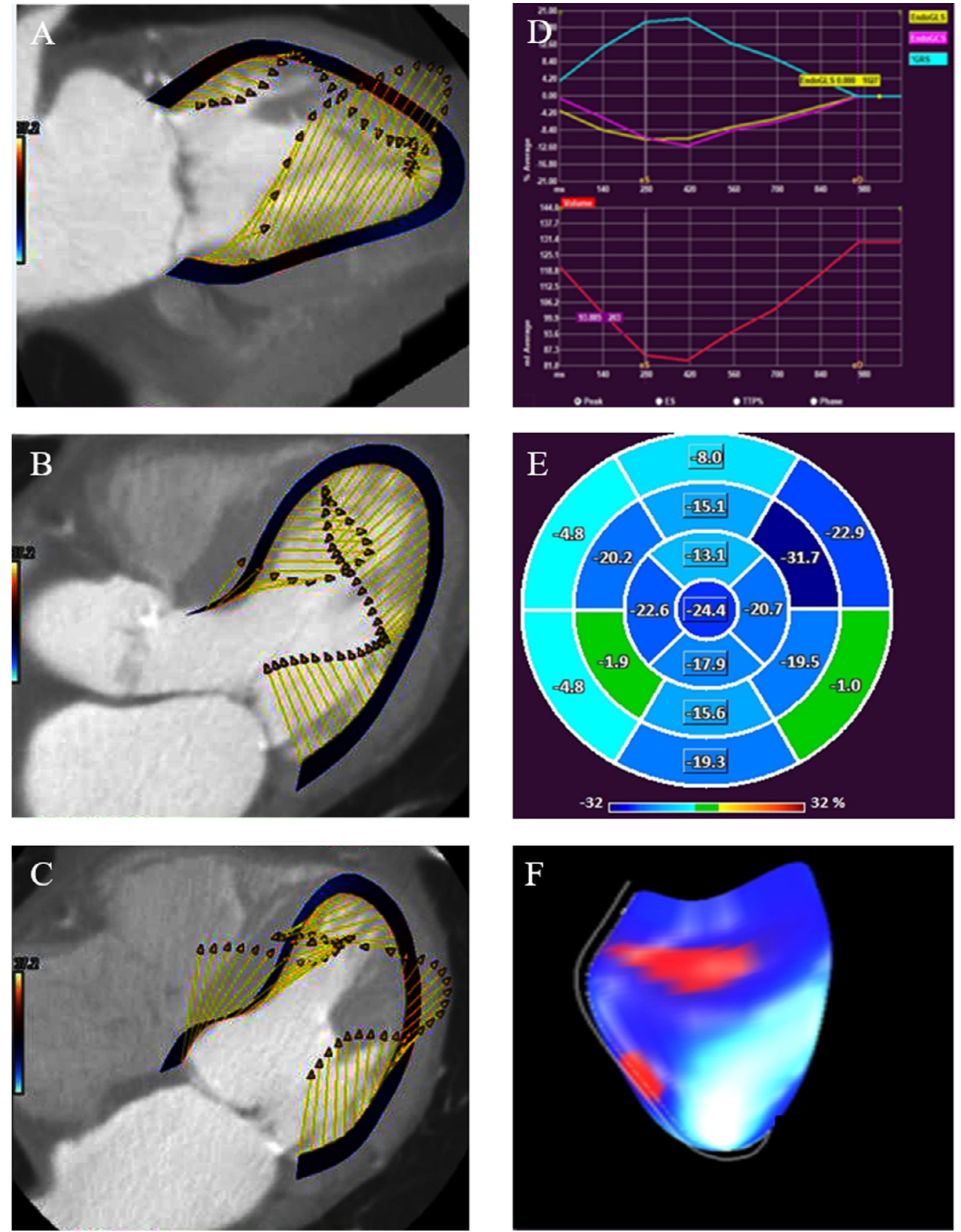

Figure 1. Assessment of left ventricular global longitudinal strain with feature tracking multi-detector row computed tomography. MDCT feature tracking in left ventricular 2-chamber (panel A), 3-chamber (panel B) and 4-chamber (panel C) views formatted via multiplanar reconstruction and processed with the help of QMass. After analysis in QMass, strain plots (Panel D), bull's eye (panel E) and dynamic MDCT 3D images (Panel F) are derived. Abbreviations: MDCT $=$ multi-detector row computed tomography. 
Medical Centre, Leiden, The Netherlands) and retrospectively analyzed. TAVI patients were followed-up at the outpatient clinic or respective referral centers. Data on allcause mortality was gathered from medical records and the municipal civil registries.

Commercially available ultrasound systems equipped with M5S transducers (Vivid-7 or E9 systems, General Electric Vingmed, Horten, Norway) were used to acquire 2-dimensional, color, continuous, and pulsed wave Doppler data from parasternal and apical views with the patient in the left lateral decubitus position. Images were stored digitally on hard disks for offline analysis (EchoPac version 202; GE Medical Systems). LV end-diastolic and end-systolic volumes were measured on the apical 2- and 4-chamber views using the Simpson's method and the LVEF was derived. ${ }^{12}$ Aortic valve peak jet velocity was estimated from continuous wave Doppler recordings obtained in the 3- or 5-chamber apical views and, if needed, on the right parasternal view using a Pedoff probe. The peak and mean transaortic pressure gradients were calculated according to the modified Bernoulli equation. The aortic valve area was calculated using the continuity equation. ${ }^{11}$

Multidetector row computed tomography scans were performed before TAVI using a 320-row computed tomography scanner (Aquilion ONE, Toshiba Medical Systems, Otawara, Japan). ${ }^{13}$ Contrast-enhanced MDCT data were acquired and data processing was performed using a remote workstation with dedicated MDCT data analysis software (Vitrea FX 1.0, Vital Images, Minnetonka, Minnesota). Additional functional reconstructions for dynamic assessment and quantification of LV GLS were created with the novel FT software (Medis Suite CT v3.1 Medis Medical Imaging Systems, Leiden, The Netherlands) (Figure 1). From the 3-dimensional multiplanar reconstructions, the 4-, 2- and 3-chamber LV views were rendered. Subsequently, the endocardial borders of the LV were traced in each view at end-diastole and end-systole and automatically interpolated to the remaining cardiac phases. LV GLS was then measured using FT, tracking of points or "features" across multiple images based on pattern-matching techniques. A point is tracked by defining a small patch around the pixel in one frame and finding the most similar patch of pixels in the next image frame allowing motion tracking through successive frames. Patients were divided according to a cut-off value of LV GLS of $-14 \%$. Patients with an FT MDCT-derived LV GLS $\leq-14 \%$ were considered to have more preserved LV systolic function whereas patients with an FT MDCT-derived LV GLS $>-14 \%$ formed the group with more impaired LV systolic function. This cut-off value was based on previous literature correlating LV GLS and prognosis in patients with severe AS. ${ }^{14}$

Continuous variables are presented as mean \pm standard deviation if normally distributed or as median and interquartile range otherwise. Categorical variables are presented as frequencies and percentages. Cumulative event rates were analyzed based on Kaplan-Meier survival method for patients with FT MDCT-derived LV GLS $\leq-14 \%$ and FT MDCTderived LV GLS >-14\% compared with the log-rank test. The association between FT MDCT-derived LV GLS and all-cause mortality was assessed with uni- and multivariable Cox regression analyses. In the multivariable analysis, clinical and echocardiographic variables known to influence the outcome of patients treated with TAVI were included. The level of significance for variables to be included in the multivariable analysis was set at $\mathrm{p}<0.10$. The hazard ratio and $95 \%$ confidence interval are presented. Statistical analysis was performed on SPSS for Windows version 23.0 (IBM, Armonk, New York). A 2-tailed p value $<0.05$ was considered statistically significant.

\section{Results}

Clinical, echocardiographic and MDCT characteristics of the overall population are presented in Tables 1 and 2 . Patients were characterized by a high prevalence of cardiovascular disease risk factors and co-morbidities. The procedural characteristics and outcomes are presented in Table 1. MDCT demonstrated a high calcification burden of the aortic valve (3134 \pm 1518 Hounsfield units) and the mean FT MDCT-derived LV GLS was $-12.5 \pm 4 \%$ (Table 2). Patients were divided into 2 groups according to a prespecified cut-off value of FT MDCT LV GLS $(\leq-14 \%$ [more preserved LV systolic function] vs $>-14 \%$ [more impaired LV systolic function]). Seventy-one (33\%) patients had FT MDCT-derived LV GLS $\leq-14 \%$ and $143(67 \%)$ a FT MDCT-derived LV GLS value $>-14 \%$.

Table 1

Baseline clinical and procedural characteristics of total TAVI population

\begin{tabular}{lc}
\hline Variable & Total population (n=214) \\
\hline Age (years) & $80 \pm 7$ \\
Men & $110(51 \%)$ \\
EuroSCORE $\geq 20$ & $83(39 \%)$ \\
Prior coronary artery disease & $130(61 \%)$ \\
Hypertension & $162(76 \%)$ \\
Hypercholesterolemia* & $145(68 \%)$ \\
Diabetes mellitus & $56(26 \%)$ \\
Peripheral vascular disease & $62(29 \%)$ \\
Current smoker & $54(25 \%)$ \\
NYHA class III-IV & $122(57 \%)$ \\
Glomerular filtration rate, (mL/min/1.73 m $\left.{ }^{2}\right)$ & $59 \pm 23$ \\
Medication & \\
B-Blocker & $126(59 \%)$ \\
Angiotensin-converting enzyme inhibitor/ & $114(53 \%)$ \\
$\quad$ Angiotensin receptor blocker & \\
Calcium channel blocker & $57(27 \%)$ \\
Diuretic & $123(57 \%)$ \\
Statin & $139(65 \%)$ \\
Aspirin and/or clopidogrel & $123(57 \%)$ \\
Vitamin K antagonist or NOAC & $76(35 \%)$ \\
Procedure related variables & \\
Moderate-severe paravalvular aortic regurgitation & $24(12 \%)$ \\
Pacemaker implantation (after TAVI) & $19(9 \%)$ \\
Complication vascular (any) & \\
Procedural approach (transfemoral) & $31(15 \%)$ \\
eurSCORE E Eura & $143(67 \%)$ \\
\hline
\end{tabular}

euroSCORE = European system for cardiac operative risk evaluation; $\mathrm{NOAC}=$ novel oral anticoagulants; $\mathrm{NYHA}=\mathrm{New}$ York Heart Association; TAVI = transcatheter aortic valve implantation.

* Hypercholeterolemia is defined as total cholesterol $>5.2 \mathrm{mmol} / \mathrm{l}$ and/or presence of lipid lowering treatment.

${ }^{\dagger}$ includes: hematoma, dissection, aneurism formation, minor and major bleeding. 
Table 2

Clinical, echocardiographic and MDCT findings in total TAVI population

\begin{tabular}{lc}
\hline Variable & $\begin{array}{c}\text { Total population } \\
(\mathrm{n}=214)\end{array}$ \\
\hline Systolic blood pressure (mm Hg) & $138 \pm 24$ \\
Diastolic Blood pressure (mm Hg) & $70 \pm 12$ \\
Pulse pressure, mm Hg (SBP-DBP) & $69 \pm 21$ \\
Pre-procedural echocardiographic findings: & \\
Aortic valve area $\left(\mathrm{cm}^{2}\right)$ & $0.8 \pm 0.2$ \\
Mean aortic valve gradient (mm Hg) & $41 \pm 18$ \\
Peak gradient (mm Hg) & $65 \pm 26$ \\
Left ventricular ejection fraction $(\%)$ & $47 \pm 10$ \\
Stroke volume index (ml/m $\left.{ }^{2}\right)$ & $44 \pm 16$ \\
Left ventricular end-diastolic volume (mL) & $94 \pm 33$ \\
Left ventricular end-systolic volume (mL) & $53 \pm 26$ \\
Left ventricle mass (g) & $211 \pm 77$ \\
Left ventricle mass index (g/m $\left.{ }^{2}\right)$ & $114 \pm 43$ \\
MDCT findings & \\
Aortic valve calcium burden (AU) & $3134 \pm 1518$ \\
FT MDCT-LV GLS $(\%)$ & $-12.5 \pm 4$ \\
\hline
\end{tabular}

FT MDCT LV GLS = feature tracking multi-detector row computed tomography derived left ventricular global longitudinal strain; GLS = left ventricular global longitudinal strain; $\mathrm{SVi}=$ stroke volume index; $\mathrm{TAVI}=$ transcatheter aortic valve implantation
During a median follow-up of 45 months (interquartile range: 29 to 62 months), 67 (31\%) patients died. The Kaplan-Meier survival analysis shows that TAVI recipients with FT MDCT-derived LV GLS >-14\% (more impaired LV systolic function) experienced higher cumulative rates of all-cause mortality, compared with patients with FT MDCT-derived LV GLS $\leq-14 \%$ (Chi-square 10.615; Log rank $\mathrm{p}=0.001$ ) (Figure 2). At 48 months of follow-up the cumulative rate of all-cause mortality for the patients with FT MDCT-derived LV GLS $\leq-14 \%$ was $15 \%$ versus $28 \%$ for the patients with FT MDCT-derived LV GLS >-14\%. On uni- and multivariate Cox-regression models, FT MDCT-derived LV GLS (as a continuous variable) demonstrated significant association with all-cause mortality (hazard ratio: $0.851 ; 95 \%$ confidence interval: 0.772 to 0.937 ; $\mathrm{p}=0.001)($ Table 3$)$.

When investigating the incremental prognostic value of FT MDCT-derived LV GLS over clinical variables and echocardiographic findings, we observed, that after the addition of LVEF to the clinical model (age, presence of coronary artery disease, and kidney function), the predictive value of the model increased (chi-square $=16.605 ; \mathrm{p}=0.045$ ), but the increase was more prominent when adding FT MDCT-derived

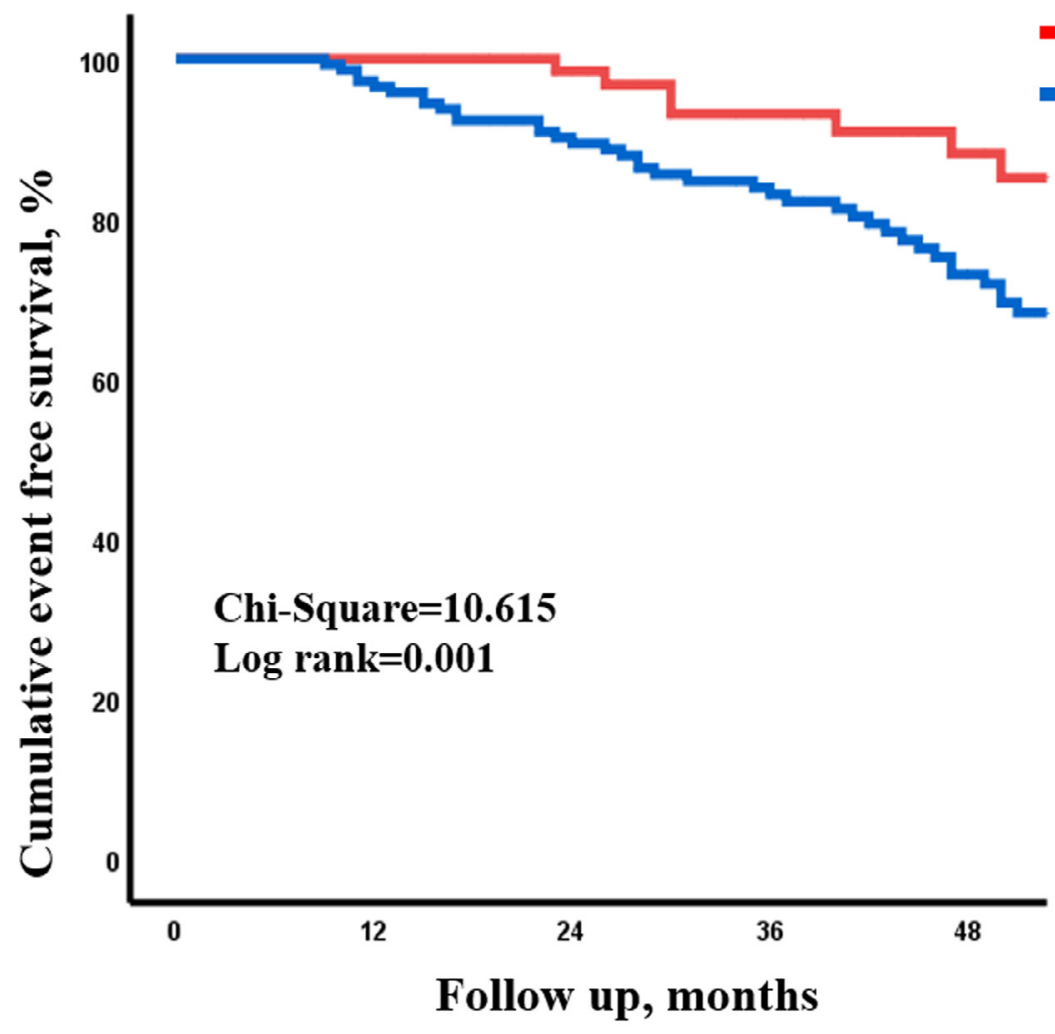

\begin{tabular}{llccc}
$\begin{array}{l}\text { GLS } \leq-14 \% \\
(n=72)\end{array}$ & 70 & 59 & 46 & 29 \\
& $(98 \%)$ & $(97 \%)$ & $(91 \%)$ & $(85 \%)$ \\
$\begin{array}{l}\text { GLS }>-14 \% \\
(n=142)\end{array}$ & 138 & 121 & 94 & 62 \\
\hline
\end{tabular}

Figure 2. Kaplan-Meier survival curves for patients treated with transcatheter aortic valve implantation, divided according to the baseline FT MDCT derived LV GLS. Abbreviations: FT MDCT = feature tracking multidetector row computed tomography; LV GLS = left ventricular global longitudinal strain. 
Table 3

Uni- and multivariable Cox regression analysis for all-cause mortality in total TAVI population

\begin{tabular}{|c|c|c|c|c|}
\hline \multirow[t]{2}{*}{ Variable } & \multicolumn{2}{|c|}{ Univariable analysis } & \multicolumn{2}{|c|}{ Multivariable analysis } \\
\hline & HR (95\% confidence interval) & $\mathrm{p}$ value & HR (95\% confidence interval) & $\mathrm{p}$ value \\
\hline Age (years) & $0.966(0.940-0.993)$ & 0.013 & $0.898(0.859-0.938)$ & $<0.001$ \\
\hline Hypertension & $0.993(0.558-1.766)$ & 0.980 & & \\
\hline Diabetes mellitus & $1.094(0.642-1.862)$ & 0.742 & & \\
\hline Prior coronary artery disease & $0.978(0.596-1.605)$ & 0.929 & $0.964(0.562-1.655)$ & 0.896 \\
\hline NYHA (class III-IV) & $1.279(0.785-2.085)$ & 0.323 & & \\
\hline Aortic valve area $\left(\mathrm{cm}^{2}\right)$ & $0.971(0.398-2.421)$ & 0.950 & & \\
\hline Aortic valve calcium score, (AU/1000) & $0.804(0.601-1.075)$ & 0.141 & & \\
\hline Mean aortic valve gradient $(\mathrm{mm} \mathrm{Hg})$ & $0.994(0.980-1.008)$ & 0.404 & & \\
\hline Left ventricular ejection fraction VEF $(\%)$ & $1.014(0.988-1.040)$ & 0.298 & $1.060(1.019-1.102)$ & 0.004 \\
\hline Left ventricular end-diastolic volume (ml) & $1.001(0.994-1.007)$ & 0.791 & & \\
\hline Significant paravalvular aortic regurgitation & $0.895(0.424-1.889)$ & 0.771 & & \\
\hline Pacemaker implantation (after TAVI) & $0.754(0.302-1.881)$ & 0.545 & & \\
\hline Complication, vascular (any)* & $0.935(0.463-1.889)$ & 0.852 & & \\
\hline
\end{tabular}

FT MDCT LV GLS = feature tracking multi-detector row computed tomography derived left ventricular global longitudinal strain; LV GLS = left ventricular global longitudinal strain; NYHA = New York Heart Association; sPAP=systolic pulmonary artery pressure; TAVI=transcatheter aortic valve implantation.

* includes: hematoma, dissection, aneurism formation, minor and major bleeding.

LV GLS to the model including clinical and echocardiographic findings $($ Chi-square $=29.187 ; \mathrm{p}<0.001)($ Figure 3$)$.

\section{Discussion}

The present study demonstrates that FT MDCT-derived LV GLS is associated with all-cause mortality in patients who underwent TAVI. Patients with impaired FT MDCTderived LV GLS showed worse survival compared with patients with more preserved FT MDCT-derived LV GLS.

MDCT is currently the imaging technique of choice to evaluate patients with severe AS who underwent TAVI. MDCT is the most reproducible and accurate method to assess the dimensions of the aortic annulus (key to select the prosthesis size) and the anatomical suitability for transfemoral access. Furthermore, MDCT provides valuable information on the severity of the AS based on calcification burden of the aortic valve (particularly in patients with discordant grading of AS based on echocardiography), anatomical relation with coronary ostia, dimensions of the aortic root and ascending aorta and information for the procedural planning such as the predicted fluoroscopic angles to safely and successfully deploy the transcatheter heart valve. ${ }^{15-20}$

With dynamic data acquired along the entire cardiac cycle, LV systolic function can be measured based on LVEF, an important parameter in the risk stratification of patients with severe AS. Currently established new MDCT technology based on detection and tracking of the endocardial border allows measurement of LV GLS. Few studies evaluating feasibility of FT MDCT-derived LV GLS are performed in AS patients with relatively small populations.
Fukui et al. observed in 123 patients who underwent TAVI therapy, that FT MDCT-derived LV GLS assessment is feasible and might be helpful in patients with sinus rhythm and difficult transthoracic echocardiographic images. ${ }^{21}$ Feasibility of MDCT-derived LV GLS was confirmed in smaller studies evaluating patients who underwent TAVI and showed improvement on short-term follow-up. . $2,23^{23}$

Studies have demonstrated that 2-dimensional transthoracic echocardiography derived LV GLS can detect early subtle myocardial dysfunction in AS patients while 2dimensional LVEF lacks accuracy to identify early changes in LV systolic function. ${ }^{8,24} \mathrm{Ng}$ et al. showed in 688 patients with AS that LV GLS is independently associated with allcause mortality. ${ }^{14}$ Vollema et al. observed in asymptomatic patients with severe AS and preserved LVEF that impaired LV GLS at baseline is associated with an increased risk for progression to the symptomatic stage and the need for aortic valve intervention. ${ }^{\gamma} \mathrm{A}$ recent meta-analysis by Magne et al. including 10 studies and 1067 asymptomatic patients with significant AS and preserved LVEF showed prognostic significance of LV GLS. $^{25}$

Fukui and coworkers have reported on the association between MDCT-derived LV GLS and outcomes of 223 patients treated with TAVI. ${ }^{26}$ The authors provided a different cut-off value of LV GLS $(-20.5 \%)$ based on receiver operating characteristic curve analysis and divided the population according to the presence of preserved LVEF with or without impaired LV GLS and patients with impaired LVEF. Patients with preserved LVEF had lower all-cause mortality as compared with patients with reduced LVEF independently of the value of LV GLS. The present study provides further insight by showing the association between 


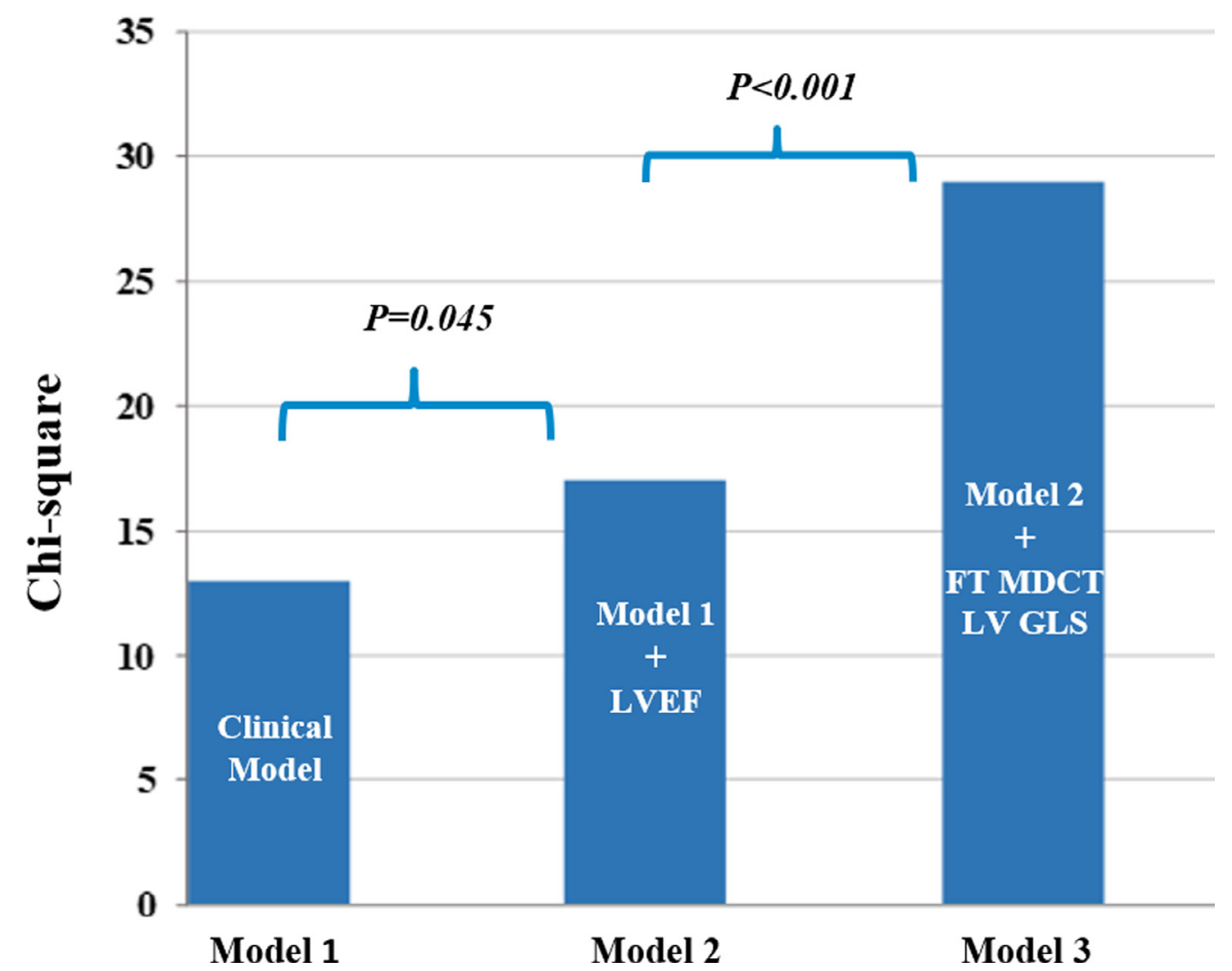

Figure 3. Prognostic value of FT MDCT LV GLS, calculated with Chi-square over clinical variables and echocardiographic findings, Model 1 (including age, presence of coronary artery disease, renal function), Model 2 (added LVEF), Model 3 (added FT MDCT LV GLS). Abbreviations: FT MDCT LV GLS = feature tracking multidetector row computed tomography derived left ventricular global longitudinal strain; LVEF $=$ left ventricular ejection fraction.

FT MDCT-derived LV GLS and all-cause mortality in severe AS patients who underwent TAVI. Patients with reduced LV longitudinal function as measured on FT MDCT showed worse survival, compared with patients with normal values of FT MDCT-derived LV GLS. The cut-off value of LV GLS was lower than that reported by Fukui et al. ${ }^{26}$ since our population has lower values of LVEF $(50.7 \pm 14.5 \%$ vs $47 \pm 10 \%$, respectively).

Since MDCT acquisition is routinely used for TAVI planning and temporal resolution of newer scanners is increasing, the additional LV GLS information from MDCT datasets might be helpful in AS patients allowing a holistic evaluation of these patients.

Some limitations should be acknowledged. First, only patients with ECG-gated MDCT data acquired throughout the entire cardiac cycle were included and therefore the present results may not be applicable to patients in whom ECGgated MDCT data acquired through the entire cardiac cycle may be challenging (eg, atrial fibrillation with high heart rate). Furthermore, there may be a selection bias that resulted in a subgroup of patients with more reduced LVEF than that reported in other series. FT MDCT-derived LV GLS has not been validated against a gold standard, such as sonomicrometry or another 3-dimensional imaging technique.

\section{Disclosures}

Tea Gegenava received funding from the European Society of Cardiology in form of an ESC Research Grant. The reference of application number is R-2017-028. The Department of Cardiology of the Leiden University Medical Center received unrestricted research grants from Biotronik, Medtronic, Bioventrix, Abbott Vascular, Boston Scientific Corporation, GE Healthcare, and Edwards Lifesciences. Jeroen J Bax and Nina Ajmone Marsan received speaker fees from Abbott Vascular. Victoria Delgado received speaker fees from Edwards Lifesciences, Abbott Vascular and Medtronic.

\section{Appendix. Author contributions}

\begin{tabular}{ll}
\hline Tea Gegenava & $\begin{array}{c}\text { Conception and design of the study; collec- } \\
\text { tion, analysis and interpretation of data; } \\
\text { drafting of the manuscript; final approval of } \\
\text { the manuscript } \\
\text { Conception and design of the study; collec- } \\
\text { tion, analysis and interpretation of data; final } \\
\text { approval of the manuscript } \\
\text { Conception and design of the study; collec- } \\
\text { tion, analysis and interpretation of data; final } \\
\text { approval of the manuscript } \\
\text { Conception and design of the study; revision } \\
\text { of the manuscript; final approval of the } \\
\text { manuscript } \\
\text { Frank van der Kley } \\
\text { Conception and design of the study; revision } \\
\text { of the manuscript; final approval of the } \\
\text { manuscript }\end{array}$
\end{tabular}

(continued) 
David Hautemann

Conception and design of the study; revision of the manuscript; final approval of the manuscript

Johannes HC Reiber

Conception and design of the study; revision of the manuscript; final approval of the manuscript

Nina Ajmone Marsan Conception and design of the study; revision of the manuscript; final approval of the manuscript

Jeroen J. Bax Conception and design of the study; revision of the manuscript; final approval of the manuscript

Victoria Delgado Conception and design of the study; collection, analysis and interpretation of data; drafting of the manuscript; final approval of the manuscript

1. Mack MJ, Leon MB, Thourani VH, Makkar R, Kodali SK, Russo M, Kapadia SR, Malaisrie SC, Cohen DJ, Pibarot P, Leipsic J, Hahn RT, Blanke P, Williams MR, McCabe JM, Brown DL, Babaliaros V, Goldman S, Szeto WY, Genereux P, Pershad A, Pocock SJ, Alu MC, Webb JG, Smith CR. Transcatheter aortic-valve replacement with a balloonexpandable valve in low-risk patients. N Engl J Med 2019;380:16951705 .

2. Leon MB, Smith CR, Mack M, Miller DC, Moses JW, Svensson LG, Tuzcu EM, Webb JG, Fontana GP, Makkar RR, Brown DL, Block PC, Guyton RA, Pichard AD, Bavaria JE, Herrmann HC, Douglas PS, Petersen JL, Akin JJ, Anderson WN, Wang D, Pocock S. Transcatheter aortic-valve implantation for aortic stenosis in patients who cannot undergo surgery. N Engl J Med 2010;363:1597-1607.

3. Leon MB, Smith CR, Mack MJ, Makkar RR, Svensson LG, Kodali SK, Thourani VH, Tuzcu EM, Miller DC, Herrmann HC, Doshi D, Cohen DJ, Pichard AD, Kapadia S, Dewey T, Babaliaros V, Szeto WY, Williams MR, Kereiakes D, Zajarias A, Greason KL, Whisenant BK, Hodson RW, Moses JW, Trento A, Brown DL, Fearon WF, Pibarot P, Hahn RT, Jaber WA, Anderson WN, Alu MC, Webb JG. Transcatheter or surgical aortic-valve replacement in intermediate-risk patients. N Engl J Med 2016;374:1609-1620.

4. Baron SJ, Arnold SV, Reynolds MR, Wang K, Deeb M, Reardon MJ, Hermiller J, Yakubov SJ, Adams DH, Popma JJ, Cohen DJ. Durability of quality of life benefits of transcatheter aortic valve replacement: long-term results from the CoreValve US extreme risk trial. Am Heart J 2017;194:39-48.

5. Falk V, Baumgartner H, Bax JJ, De Bonis M, Hamm C, Holm PJ, Iung B, Lancellotti P, Lansac E, Munoz DR, Rosenhek R, Sjogren J, Tornos Mas P, Vahanian A, Walther T, Wendler O, Windecker S, Zamorano JL. 2017 ESC/EACTS guidelines for the management of valvular heart disease. Eur J Cardiothorac Surg 2017;52:616-664.

6. Treibel TA, Scully PR, Moon JC. Myocardial hypertrophy, matrix expansion, and focal scar: progression and regression in aortic stenosis. Circ Cardiovasc Imaging 2018;11:e007975.

7. Vollema EM, Sugimoto T, Shen M, Tastet L, Ng ACT, Abou R, Marsan NA, Mertens B, Dulgheru R, Lancellotti P, Clavel MA, Pibarot P, Genereux P, Leon MB, Delgado V, Bax JJ. Association of left ventricular global longitudinal strain with asymptomatic severe aortic stenosis: natural course and prognostic value. JAMA Cardiol 2018;3:839-847.

8. Kusunose K, Goodman A, Parikh R, Barr T, Agarwal S, Popovic ZB, Grimm RA, Griffin BP, Desai MY. Incremental prognostic value of left ventricular global longitudinal strain in patients with aortic stenosis and preserved ejection fraction. Circ Cardiovasc Imaging 2014;7: 938-945.

9. Kearney LG, Lu K, Ord M, Patel SK, Profitis K, Matalanis G, Burrell LM, Srivastava PM. Global longitudinal strain is a strong independent predictor of all-cause mortality in patients with aortic stenosis. Eur Heart J Cardiovasc Imaging 2012;13:827-833.

10. Chin CW, Pawade TA, Newby DE, Dweck MR. Risk stratification in patients with aortic stenosis using novel imaging approaches. Circ Cardiovasc Imaging 2015;8:e003421. https://doi.org/10.1161/CIRCIMAGING.115.003421.

11. Baumgartner HC, Hung JC-C, Bermejo J, Chambers JB, Edvardsen T, Goldstein S, Lancellotti P, LeFevre M, Miller F Jr., Otto CM.
Recommendations on the echocardiographic assessment of aortic valve stenosis: a focused update from the European Association of Cardiovascular Imaging and the American Society of Echocardiography. Eur Heart J Cardiovasc Imaging 2017;18:254-275.

12. Lang RM, Badano LP, Mor-Avi V, Afilalo J, Armstrong A, Ernande L, Flachskampf FA, Foster E, Goldstein SA, Kuznetsova T, Lancellotti P, Muraru D, Picard MH, Rietzschel ER, Rudski L, Spencer KT, Tsang W, Voigt JU. Recommendations for cardiac chamber quantification by echocardiography in adults: an update from the American Society of Echocardiography and the European Association of Cardiovascular Imaging. Eur Heart J Cardiovasc Imaging 2015;16:233270.

13. van Rosendael PJ, Kamperidis V, Kong WK, van Rosendael AR, Marsan NA, Bax JJ, Delgado V. Comparison of quantity of calcific deposits by multidetector computed tomography in the aortic valve and coronary arteries. Am J Cardiol 2016;118:1533-1538.

14. Ng ACT, Prihadi EA, Antoni ML, Bertini M, Ewe SH, Ajmone Marsan N, Leung DY, Delgado V, Bax JJ. Left ventricular global longitudinal strain is predictive of all-cause mortality independent of aortic stenosis severity and ejection fraction. Eur Heart J Cardiovasc Imaging 2018;19:859-867.

15. Gurvitch R, Webb JG, Yuan R, Johnson M, Hague C, Willson AB, Toggweiler S, Wood DA, Ye J, Moss R, Thompson CR, Achenbach S, Min JK, Labounty TM, Cury R, Leipsic J. Aortic annulus diameter determination by multidetector computed tomography: reproducibility, applicability, and implications for transcatheter aortic valve implantation. JACC Cardiovasc Interv 2011;4: $1235-1245$.

16. Podlesnikar T, Prihadi EA, van Rosendael PJ, Vollema EM, van der Kley F, de Weger A, Ajmone Marsan N, Naji F, Fras Z, Bax JJ, Delgado $\mathrm{V}$. Influence of the quantity of aortic valve calcium on the agreement between automated 3-dimensional transesophageal echocardiography and multidetector row computed tomography for aortic annulus sizing. Am J Cardiol 2018;121:86-93.

17. Messika-Zeitoun D, Serfaty JM, Brochet E, Ducrocq G, Lepage L, Detaint D, Hyafil F, Himbert D, Pasi N, Laissy JP, Iung B, Vahanian A. Multimodal assessment of the aortic annulus diameter: implications for transcatheter aortic valve implantation. J Am Coll Cardiol 2010; $55: 186-194$

18. Prihadi EA, van Rosendael PJ, Vollema EM, Bax JJ, Delgado V, Ajmone Marsan N. Feasibility, accuracy, and reproducibility of aortic annular and root sizing for transcatheter aortic valve replacement using novel automated three-dimensional echocardiographic software: comparison with multi-detector row computed tomography. J Am Soc Echocardiogr 2018:31. 505-514.e503.

19. Genereux P, Head SJ, Hahn R, Daneault B, Kodali S, Williams MR, van Mieghem NM, Alu MC, Serruys PW, Kappetein AP, Leon MB. Paravalvular leak after transcatheter aortic valve replacement: the new Achilles' heel? a comprehensive review of the literature. J Am Coll Cardiol 2013;61:1125-1136.

20. Lerakis S, Hayek SS, Douglas PS. Paravalvular aortic leak after transcatheter aortic valve replacement: current knowledge. Circulation 2013;127:397-407.

21. Fukui M, Xu J, Abdelkarim I, Sharbaugh MS, Thoma FW, Althouse AD, Pedrizzetti G, Cavalcante JL. Global longitudinal strain assessment by computed tomography in severe aortic stenosis patients - feasibility using feature tracking analysis. J Cardiovasc Comput Tomogr 2019;13:157-162.

22. Marwan M, Ammon F, Bittner D, Rother J, Mekkhala N, Hell M, Schuhbaeck A, Gitsioudis G, Feyrer R, Schlundt C, Achenbach S, Arnold M. CT-derived left ventricular global strain in aortic valve stenosis patients: a comparative analysis pre and post transcatheter aortic valve implantation. J Cardiovasc Comput Tomogr 2018;12:240-244.

23. Ammon F, Bittner D, Hell M, Mansour H, Achenbach S, Arnold M, Marwan M. CT-derived left ventricular global strain: a head-to-head comparison with speckle tracking echocardiography. Int J Cardiovasc Imaging 2019

24. Ng AC, Delgado V, Bertini M, Antoni ML, van Bommel RJ, van Rijnsoever EP, van der Kley F, Ewe SH, Witkowski T, Auger D, Nucifora G, Schuijf JD, Poldermans D, Leung DY, Schalij MJ, Bax JJ. Alterations in multidirectional myocardial functions in patients with aortic stenosis and preserved ejection fraction: a two-dimensional speckle tracking analysis. Eur Heart J 2011;32:1542-1550. 
25. Magne J, Cosyns B, Popescu BA, Carstensen HG, Dahl J, Desai MY, Kearney L, Lancellotti P, Marwick TH, Sato K, Takeuchi M, Zito C, Casalta AC, Mohty D, Pierard L, Habib G, Donal E. Distribution and prognostic significance of left ventricular global longitudinal strain in asymptomatic significant aortic stenosis: an individual participant data meta-analysis. JACC Cardiovasc Imaging 2019;12:84-92.
26. Fukui M, Xu J, Thoma F, Sultan I, Mulukutla S, Elzomor H, Lee JS, Gleason TG, Cavalcante JL. Baseline global longitudinal strain by computed tomography is associated with post transcatheter aortic valve replacement outcomes. J Cardiovasc Comput Tomogr 2019. (in press). pii: S1934-5925(19)30429-0. https://doi.org/10.1016/j.jcet. 2019.12.002. 